\title{
M\&As get another assist: when CEOs add intuition to the decision mix
}

Hannu Kuusela, Siiri Koivumäki, and Mika Yrjölä*

*Corresponding author

\section{AUTHOR VERSION OF:}

Hannu Kuusela, Siiri Koivumäki, Mika Yrjölä, (2019) "M\&As get another assist: when CEOs add intuition to the decision mix", Journal of Business Strategy, https://doi.org/10.1108/JBS-01-2019-0021

Hannu Kuusela

Professor, Tampere University

Finland

Siiri Koivumäki

Product Manager, Saarioinen

Finland

Mika Yrjölä

mika.yrjola@tuni.fi

University Lecturer, Tampere University

Finland 


\title{
M\&As get another assist: when CEOs add intuition to the decision mix
}

\begin{abstract}
:
Purpose - The purpose of this study is to analyze the use of intuition in successful merger and acquisition $(\mathrm{M} \& \mathrm{~A})$ decisions. $\mathrm{M} \& \mathrm{As}$ are strategic decisions that can create growth, open up new markets, and strengthen the company's position and competence portfolio. Strategic decisions involve, by their very nature, considerable investments and have company-wide and long-lasting implications. At the same time, the decision-makers have access to large amounts of data from various sources, but this data is often uncertain and inaccurate and entails numerous assumptions. Therefore, M\&A decisions are only rational to a degree, and emotional elements, such as intuition, likely play a significant role.
\end{abstract}

Design/methodology/approach - Acknowledging how critically important, but also how difficult, M\&As are, the authors analyzed nine instances (cases) of successful acquisitions in which the executives believed that the role of intuition was critical.

Findings - The findings show that intuition in strategic decision-making emerges on three levels: individual, collective, and environmental.

Practical implications - This paper encourages top executives to proactively acknowledge and take advantage of intuition in their strategic decision-making. We propose a framework to help with these endeavors.

Originality/value - This paper contributes by highlighting that intuition is not just a factor on an individual level: it can also surface from group interactions as well as the environment. Surprisingly, all the executives interviewed spoke of the positive effects that intuition can have on acquisition decisions. This is in contrast to the dominant view that considers intuition as nonrational and even as a form of bias.

Keywords: Strategy, Executive, Intuition, Mergers and acquisitions

Word count (3500-5000): 3650 (without abstract, tables, figures, or references) 


\section{Introduction}

Growth is a necessary element for the success of many companies and organizations, and one of the most important responsibilities of the top management is to create growth by finding new opportunities to grow and by securing the preconditions for growth. Growth can be organic, such as from new products or marketing initiatives, or non-organic, in the form of mergers and acquisitions (M\&As). M\&As are an essential component to many corporate strategies, as they can secure access to new markets, resources, or competencies. Nonetheless, corporate acquisitions have a poor track record. For instance, Gubbi et al. (2010) estimate a 60-70 percent failure rate for international acquisitions, while Joshi et al. (2018) estimate that between 70 and 90 percent of M\&As fail. Multiple factors have been identified to explain these failures, such as the overconfidence and inaccurate estimations of synergies, errors in negotiations and planning, and cultural and organizational identity issues (Du and Jaw, 2018; Joshi et al., 2018).

M\&As represent strategic decisions that are, by their very nature, complex and time-consuming processes, even with considerable past experience from similar decisions. These decisions are non-routine and company-wide, involve considerable investments (in the form of financial, temporal, human, or other resources), and have long-lasting implications. Further, they entail considerable advanced preparations to be made by different people and organizations and are based on a range array of information and different types of analyses. In such a decision-making situation, it is necessary to combine previous experiences with information from the potential acquisition target as well as estimates of the future. In short, the decision must be based on factual and, to a large extent, non-factual information that is laden with uncertainty.

Decision-making in uncertain situations has been approached in different ways in the literature, such as in studies of decision-making biases. An emerging approach is to study the intuitive elements in such decisions. Intuitions are "affectively charged judgments that arise through rapid, nonconscious, and holistic associations" (Dane and Pratt, 2007, p. 40). They involve context-specific, affective, and expertise-based elements but have usually been treated as a form of bias that negatively affects decisions (Akinci and Sadler-Smith, 2018). This paper 
focuses on their use in strategic decision-making. More concretely, the purpose is to analyze how intuition manifests in successful M\&A decisions based on the experiences of CEOs.

\section{Intuitive decision-making}

Intuition has been characterized in a variety of ways in the literature. First, it is a fast, automatic, and unconscious process (Dane and Pratt, 2007). Second, it is rooted in past experiences and knowledge (Dane and Pratt, 2007; Salas, Rosen, and Diaz Granados, 2010; Shapiro and Spence, 1997). Third, intuitive decision-making uses these past experiences to find similarities, regularities, or formulas, and it makes associations in order to reach a solution (Dane and Pratt, 2007; Miller and Ireland, 2005). Fourth, this type of decision-making involves affective and emotional elements, such as gut feelings, that the individual is usually unable to express or describe in words (Dane and Pratt, 2007; Shapiro and Spence, 1997).

Intuition affects decision-making in numerous ways (e.g. Miller and Ireland, 2005). Following from its key characteristics, it is rapid and can therefore speed up decision-making. Intuiting can also initiate decision-making processes and allow for decisions to be made without data (Burke and Miller, 1999). Further, it has been found to contribute to effectiveness, especially in complex, time-pressured decision-making scenarios; however, overly relying on it can lead to errors (Salas et al., 2010).

This topic is especially relevant for top executives, since it is their task to make strategic and far-reaching decisions under time pressures, ambiguity, uncertainty, and conditions of change. We thus conclude that executives should address intuition in their strategic decision-making, such as in M\&A decisions. For instance, being aware of one's own and other's intuitive judgments can help develop organizational decision-making. Similarly, intuiting can act as a kind of early warning system and prevent risky decisions from being made. Therefore, executives should acknowledge and take advantage of it in strategic decision-making. 


\section{Illustrative examples of the use of intuition}

\subsection{Data}

We adopt a qualitative methodology to analyze the use of intuition in successful M\&A decisions. We used theoretical sampling (i.e. the principle of generating data that is likely to be the most interesting) to choose individual executives of different companies that had recently undergone successful M\&As. We collected illustrative examples of successful acquisition decisions in which intuitive decision-making played a critical role (whether positive or negative). To ensure a rich sample, we looked for companies that represented a wide variety of industries and for acquisition types that were both national and international in nature and that represented various strategies, such as market extension, capacity extension, and technology acquisition.

Table 1. Research data

\begin{tabular}{|c|c|c|c|c|c|}
\hline \multirow{2}{*}{$\begin{array}{l}\text { Example } \\
\text { organization }\end{array}$} & \multirow{2}{*}{$\begin{array}{l}\text { Informant's title } \\
\text { and years of } \\
\text { experience }\end{array}$} & \multicolumn{2}{|c|}{ Size of organization } & \multirow{2}{*}{$\begin{array}{l}\text { Type of } \\
\text { organization }\end{array}$} & \multirow[t]{2}{*}{ Type of acquisition } \\
\hline & & $\begin{array}{l}\text { No. } \\
\text { employees }\end{array}$ & $\begin{array}{l}\text { Revenue in } \\
\text { million } \\
\text { euros }\end{array}$ & & \\
\hline A & CEO, 32 years & 1190 & 280 & Food industry & $\begin{array}{l}\text { Company acquisition to } \\
\text { drive international } \\
\text { market expansion }\end{array}$ \\
\hline B & $\begin{array}{l}\text { Vice-CEO, } 17 \\
\text { years }\end{array}$ & 1480 & 340 & $\begin{array}{l}\text { Personnel } \\
\text { transportation }\end{array}$ & $\begin{array}{l}\text { Acquiring a company to } \\
\text { create more capacity }\end{array}$ \\
\hline $\mathrm{C}$ & CEO, 12 years & 1480 & 6300 & Retail & $\begin{array}{l}\text { International market } \\
\text { expansion; acquiring } \\
\text { new competencies and } \\
\text { resources }\end{array}$ \\
\hline $\mathrm{D}$ & CEO, 20 years & 800 & 100 & $\begin{array}{l}\text { Public- } \\
\text { private } \\
\text { healthcare }\end{array}$ & $\begin{array}{l}\text { Merging operations to } \\
\text { build market share }\end{array}$ \\
\hline $\mathrm{E}$ & CEO, 25 years & 200 & 1000 & Real estate & $\begin{array}{l}\text { Acquiring a company to } \\
\text { create more capacity }\end{array}$ \\
\hline $\mathrm{F}$ & CEO, 24 years & 7830 & 3500 & Utilities & $\begin{array}{l}\text { International market } \\
\text { expansion }\end{array}$ \\
\hline $\mathrm{G}$ & CEO, 35 years & 80 & 11 & Healthcare & Expanding operations \\
\hline
\end{tabular}




\begin{tabular}{llccll}
\hline $\mathrm{H}$ & CEO, 30 years & 370 & 39 & $\begin{array}{l}\text { Construction } \\
\text { engineering } \\
\text { services }\end{array}$ & $\begin{array}{l}\text { Industry expansion and } \\
\text { geographical expansion }\end{array}$ \\
\hline I & CEO, 10 years & 525 & 23 & $\begin{array}{l}\text { High growth } \\
\text { company }\end{array}$ & $\begin{array}{l}\text { Industry expansion and } \\
\text { geographical expansion }\end{array}$ \\
\hline
\end{tabular}

The research was carried out by interviewing nine CEOs (Table 1), which is in line with Easton's (2010) suggestion for the ideal number of cases to be between four and 10. More precisely, we used the critical incident technique (CIT; Gremler, 2004) to get the informants to share their thoughts on using intuition in the specific critical decision-making case (cf. Sinclair, 2014). Each executive therefore recounted an instance of a successful acquisition in which he or she reported that the role of intuition was critical. Before each interview, we familiarized ourselves with the organization's current situation and strategy and also with its history. The unit of analysis was the M\&A decision process or, more specifically, the moment when the choice was made whether or not to buy the target company. The informants' accounts were analyzed using content analysis techniques to uncover the different ways and levels through which intuition emerged in strategic decision-making. These findings are discussed next.

\subsection{The different levels through which intuition emerges in strategic decision- making}

As expected, the executives all reported that intuition played a critical role in the acquisition decision. More surprising, however, was that these effects were seen as largely positive, and only a few had experienced negative effects, such as the fact that intuitive, emotionally-laden decisions might be difficult to reverse; intuitive judgments, even if correct, might lead to incorrect timing; or intuition, while simplifying decision-making, might close off alternatives that later transpire to be beneficial. The positive outcomes included being able to spot weak signals and anticipate marketplace changes; being able to perceive invisible information, such as in social situations (e.g. getting a "vibe" from the negotiation partners); and being able to make sense of large amounts of data. As another example, informant A described how intuition can also act as an early warning system, saying that it "relates to a certain feeling. It can either be a sense of danger or a sense that this course is right. It might be a prolonged feeling that 
guides how I lead and manage" (CEO, Food industry). The most interesting finding was that intuitive strategic decision-making was more than an individual level, psychological phenomenon. It emerged on three levels: individual, collective, and environmental (Table 2), which are discussed next.

Table 2. The three levels of intuition

\begin{tabular}{|c|c|c|}
\hline Level & Factors & Illustrative quote \\
\hline Individual & $\begin{array}{l}\text { - Curiosity and the ability to see } \\
\text { opportunities and perceive "the big } \\
\text { picture" without fully relying on } \\
\text { documented, factual information } \\
\text { - The courage to seize opportunities } \\
\text { and make decisions } \\
\text { - Using one's (industry) experience and } \\
\text { expertise }\end{array}$ & $\begin{array}{l}\text { "In my opinion, curiosity is probably } \\
\text { linked to intuition. A person who is } \\
\text { very interested in their surrounding } \\
\text { environment and events is, most } \\
\text { likely, more intuitive than someone } \\
\text { who doesn't possess curiosity. This is } \\
\text { because intuition has to be based on } \\
\text { something, some source of } \\
\text { information, and if you are curious, } \\
\text { then you are constantly building an } \\
\text { intuitive understanding of the world" } \\
\text { (A, CEO, Food industry). }\end{array}$ \\
\hline Collective & $\begin{array}{l}\text { - Interaction and discussions with } \\
\text { others } \\
\text { - Seeking and receiving feedback }\end{array}$ & $\begin{array}{l}\text { "I know that it can be more than one } \\
\text { person's intuition. A collective } \\
\text { intuition is when people who think in a } \\
\text { similar manner strengthen the } \\
\text { intuition, which is formed as a } \\
\text { synthesis" (D, CEO, Public-private } \\
\text { healthcare). }\end{array}$ \\
\hline Environmental & $\begin{array}{ll}\text { - } & \text { Market disruption and uncertainty } \\
\text { - } & \text { Regulatory environment } \\
\text { - } & \text { Decision-making culture and } \\
& \text { procedures }\end{array}$ & $\begin{array}{l}\text { "Lastly, I want to emphasize that you } \\
\text { should be seeking intuitions across } \\
\text { industry boundaries. You could talk to } \\
\text { your business partners and that way try } \\
\text { to chase intuition" (B, Vice-CEO, } \\
\text { Personnel transportation). }\end{array}$ \\
\hline
\end{tabular}


Individual level

Intuitiveness is rooted in the individual and their persona, experiences, and characteristics. Therefore, the individual-level findings relate to: curiosity and the ability to see opportunities and perceive the "big picture" without fully relying on documented, factual information; the courage to seize opportunities and make decisions; and using one's (industry) experience and expertise.

In relation to how intuition emerges on an individual level, the informants highlighted curiosity and creative thinking as its drivers. Curiosity involved being open to new ideas and looking for information from multiple sources. Here, informant B (Vice-CEO, Personnel transportation) remarked that it is dangerous to have decision-making concepts and procedures that are too well-defined, as they might restrain intuiting, stating, "You need to have some basic rules, but if you're too tied up with concepts and formulas, then you won't be able to produce intuitions." Being curious and creative also enables decision-makers to sense new opportunities and establish a "big picture" view of the decision:

Basically, intuition can be this sort of a big picture, so that it is the vision in some way. And, often, the big picture is formed of pieces, so then intuition is the ability to understand the whole, what we are trying to achieve here and what the prerequisites are in order for the pieces to come together, and what prevents them from doing so. ( $D, C E O$, Public-private healthcare)

Courage was another individual-level driver of intuitiveness. The informants said how intuiting enabled them to be different from their competitors or the established market practices. Informant F explained, 'I guess it's my intuition or point of view that lets me be brave enough to do things differently than everyone else" (CEO, Utilities). The informant further remarked that actively not following the competition had, in his experience, enabled the company to make more impactful decisions that were successfully timed. Conversely, informant B remarked that using intuitive judgments requires boldness, saying, "And this is the big problem: 
what stops intuitiveness and innovation is, ultimately, accountability. Who's willing to take the shot?" (Vice-CEO, Personnel transportation).

Naturally, intuitiveness in expert decision-making is based on the decision-maker's (industry) experience and expertise, and the informants' responses confirm this. They described this with phrases such as, "using lessons of the past to make inferences and decisions regarding the future" (C, CEO, Retail). Informant G (CEO, Healthcare) spoke of continuously absorbing information from the environment and letting time pass so that, eventually, an intuitive judgment will emerge as a eureka moment. Informant E, as another example, remarks,

Of course, there is everything that I've experienced in the past in the background. I, as an executive and a decision-maker, have been living, seeing, experiencing, and succeeding, and banging my head to the wall. It [intuition] must come from there somehow. In my decisions, all this is integrated into it. (CEO, Real estate)

Overall, the informants saw that individual-level intuitiveness is the sum of curiosity, courage, and experience. While the informants viewed curiosity as a trait that provides fuel for intuitive judgments, courage was seen as the capacity to actually make the decisions based on these judgments. Experience and expertise, including general managerial experience, experience from similar decisions, and knowledge gained from working in the industry, are the basic fuel for intuitive decision-making (Salas, 2010).

\section{Collective level}

Intuition can also emerge through the collective level. For instance, the informants spoke of how discussions from multiple perspectives can bring it about. It can come about in more formal sessions, such as competitor analyses, or in more informal ones, such as team sparring sessions. In such cases, intuiting and intuitive judgments are shared and shaped by the group. 
Intuition is, of course, a human thing, so it has something to do with the individual and their personality, but at the same time, it also relates to the spirit and dynamics [...] It is not bound to one person, it is part of the [decision-making] entity. (I, CEO, High growth company)

The whole management team felt - there was [...] a collective intuition that this was a good decision. (A, CEO, Food industry)

The group's interactions and discussions shape intuitions. For example, according to informant B, "A discussion with multiple perspectives can bring about an intuition" (Vice-CEO, Personnel transportation). Others also expressed how viewing the decision-making problem from multiple angles and challenging others' perspectives could generate or enhance intuitive decision-making. While these interactions can bring this about, some group interactions may also prevent it from emerging. For example, informant D reflected that some personality types, such as those relying more on systematic and rational analysis (e.g. "a traditional lawyer type"), might hold a skeptical attitude toward intuitive decision-making and try to undermine its use in strategic discussions and decisions. Ultimately, the informants felt that a shared intuition was beneficial, in the sense that it resulted in a shared goal or vision. This could help achieve a buy-in and a commitment to a decision. As an example, informant A (CEO, Food industry) described how the company's top management team formed a shared sense of inspiration and vision to purchase and overhaul a smaller competitor. Informant A attributes this successful acquisition to the intuitive vision and commitment shared by the team.

The second important finding that was related to the collective level was the importance of seeking and receiving feedback. Because M\&A decisions and their consequences unfold over a period of years, the ultimate result and feedback is difficult to obtain and assess. Meanwhile, the informants spoke of the need to actively seek feedback from multiple sources concerning different aspects of the decision-making process. For example, one CEO said, "I easily form opinions and assumptions about different topics, and I need to actively challenge quite a number of people to get them to question me and, in this way, find the arguments [behind the assumptions]" (A, CEO, Food industry). The informants also mentioned the importance of giving feedback to their team, subordinates, and peers, thereby enhancing the collective intuitiveness. 
Overall, collective-level intuitive decision-making was seen to be the result of group interactions, including both formal and informal discussions and feedback. The informants especially emphasized that intuitive decision-making on the collective level is a process, in which the group members (e.g. the top management team) all shape the decision by contributing their own viewpoints and feedback.

\section{Environmental level}

The decision-making environment or context can also bring about intuitive decision-making. The environmental-level factors include both the organization's internal factors and external factors, such as the decision-making culture, time pressures, market conditions, and regulatory environment. External factors relate to shifts and disruptions occurring in the market. For instance, the CEO of a utilities company reflects that, "If I think about our industry, then things like political decisions, regulation and codes, and climate policy are very relevant. They can unexpectedly provide inputs that force you to rethink your point of view" (F). The CEO of a retail company remarked how one intuitive acquisition process was sparked by competitor moves in the market (C). Others also said that they used intuition to spot and anticipate larger trends in the market. For example, informant $G$ reflected that he intuitively anticipated the demand trends by synthesizing the information on aspects such as the local economic growth, the status of large economies, and the global economy. Further, the informants stressed that factors such as industry practices, regulatory frameworks, and reporting requirements all potentially inhibit intuitive decision-making. Nonetheless, the executives felt the need to work around these constraints and proactively monitor their environment. Informant D remarks:

As I said before, intuition somehow takes shape from past experiences and the things you know about your company's environment. Then, if you perceive an unknown object, say, a potential target for a business acquisition, you can sort of make a gut feeling judgment of that target based on similar experiences and your knowledge of the environment. You form an intuitive judgment of the value of that target and the level of difficulty 
involved in the acquisition and, ultimately, whether it's worth doing. (CEO, Public-private healthcare)

As for internal factors, the informants highlighted the importance of the decision-making culture, climate, and policies for intuitive decisions. The informants spoke highly of nonstructured or loosely structured strategic decision processes, meaning that they advocated moving away from detailed analyses and a miniscule level of detail. Instead, the decisionmaking culture should be open to accept both rational aspects and emotional viewpoints as inputs for strategic decisions: "There's always room for new ideas, always" (B, Vice-CEO, Personnel transportation). Further, current management trends were seen to "kill the use of intuitive decision-making styles" ( $\mathrm{H}, \mathrm{CEO}$, Construction engineering services) by focusing too much on quantitative analyses. As a final point, the corporate culture was seen as crucial in either sparking or stopping the use of intuitive decision-making. In particular, the heterogeneity of the organizational members was seen to be important, in terms of cross-functionality and inter-disciplinary interaction.

\section{I very much believe in interdisciplinarity. I believe in the strength of the culture. People are not people if there's no culture, and culture is, in turn, a part of emotional intelligence. (H, CEO, Construction engineering services)}

In sum, the environment and context, including the organization's internal and external factors, bring about intuitive decision-making, according to the informants. External factors can provide important signals as inputs to intuitive decisions, but they also create the conditions that enhance intuitiveness (e.g. uncertainty, ambiguity, and complexity). Internal factors, such as the decision-making culture, also relate to these conditions and can, to some extent, be controlled or influenced by the executives. 


\section{Discussion}

The findings presented above seem to support the notion that intuition plays a critical role in strategic decision-making and surfaces on multiple levels. This notion gives rise to some implications.

First, intuition seems to be an irremovable part of strategic decision-making, as it manifests itself in strategic decisions on various levels (i.e. individual, collective, and environmental). Therefore, executives need to accept that it is present in important strategic decisions. Moreover, we encourage executives to confidently create space for intuitive decision-making in order to take full advantage of it. Even simply stating that decisions should not be overanalyzed (or, in the words of informant A, "analyzed to death") is a signal that creates room for intuitiveness. Additionally, delaying a decision, such as taking a short break during the meeting, can give individuals the time and space to develop and express their intuitions.

Second, in our data, the benefits of intuitive decision-making outweighed the drawbacks. Therefore, it might be harmful for executives to think of intuitiveness in terms of decisionmaking biases (cf. Akinci and Sadler-Smith, 2018) that might lead to poor decisions. Executives should instead trust and systematically make use of intuitive decision-making without prejudices or fears concerning bias or irrationality. Further, we argue that intuitive decision-making should not replace fact-based, logical reasoning but should complement it. Informant I (CEO, High growth company), for example, explained that he would only make a strategic decision if both the available factual evidence and his own intuitive judgment supported it. An interesting consideration related to this balance of analytical and intuitive decision-making is the sequencing and timing of these two types of decision-making within the decision process. For instance, executives could start with a detailed analysis and then purposefully create a space and situation for intuitiveness to emerge on the individual, collective, or environmental level. Alternatively, they could routinely create the conditions that boost intuitiveness and only later turn to detailed analyses and reasoning as the need arises. There is probably not a one-size-fits-all solution to these concerns, and we therefore encourage 
executives to experiment with different approaches to find one that fits their specific organizational context and decision-making culture.

Third, when reflecting on the findings, it is clear that intuition is not just a factor of individual cognition but can also emerge from the group/collective as well as from the environment. Executives aiming to create more space for intuitive decision-making should keep these collective and environmental levels in mind. For instance, the decision-making culture should not be overly cautious of biases. The importance of feedback for developing expert intuitions, which was also recognized in previous studies (Salas, 2010), was situated at the collective level, because seeking, receiving, and giving feedback occurs in a social context and enhances the intuitiveness of the collective, not just the individual.

Building on the above discussion, we propose a framework for executives to take full advantage of this type of strategic decision-making (Figure 1). This framework is based on the finding that intuitive decision-making can emerge on three different levels (individual, collective, environmental) and that executives can proactively influence its use in their organizations. For example, on the individual level, executives could develop their own curiosity by combining the traditional industry reports and market analyses with other information that reflect different viewpoints. On the collective level, one initiative that could boost intuitiveness is establishing better feedback mechanisms, such as having every team member take a turn as the devil's advocate. As an example of an environmental-level initiative, the executives can set an example through their own behavior in order to shape the organization's culture in a direction that allows both analytical and intuitive decision-making styles. 
Figure 1. A framework for taking full advantage of intuition in strategic decision-making

\section{$\underline{\text { Level }}$}

Individual: the individual intuitions and traits that advance intuition

Collective: the collective intuitions and behaviors that advance intuition

Environmental: the environment and context of the decision-making

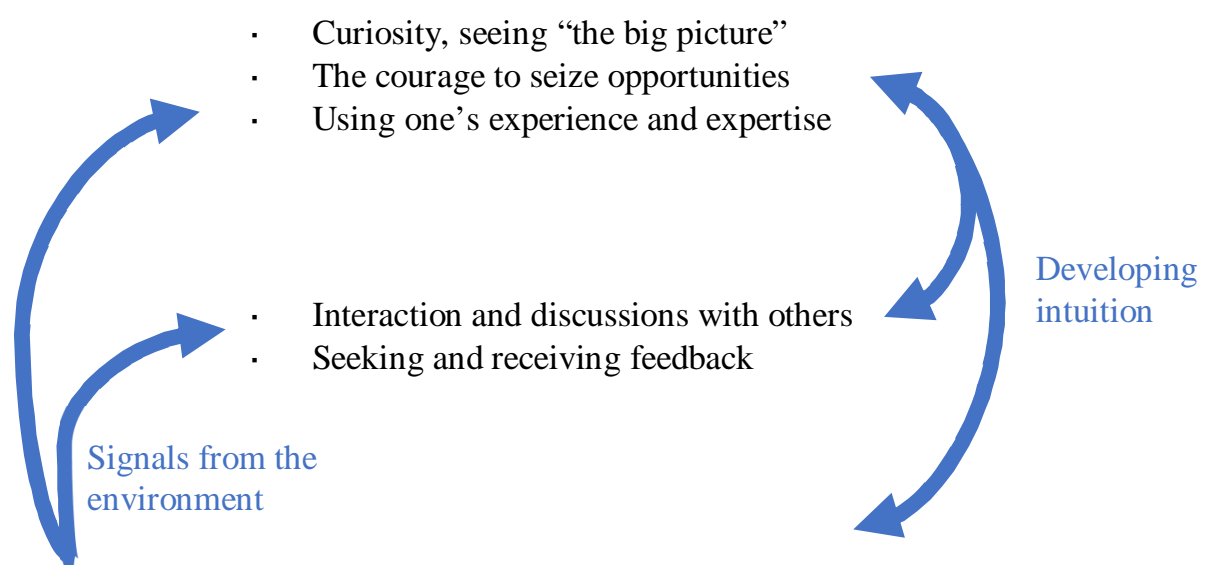

- Market disruption and uncertainty

- Regulatory environment climate, and procedures
- Decision-making culture,

The drawbacks of intuitive decision-making are well-documented (Akinci and Sadler-Smith, 2018), which is why they were not discussed in detail in this paper. We hope this study inspires more research into the potential advantages of intuitive decision-making, especially in relation to strategic decisions, which involve considerable uncertainty about the future. While the current study focused on M\&As, other types of strategic decisions, such as entering new markets, forming alliances, or changing the organization's business model, should also be analyzed. We also encourage future research to broaden the research perspective from individual to collective and environmental intuitions. Our research focused on successful decisions in which intuition played a significant role. It would be interesting to see future studies investigate the decisions that were not taken, because intuition can also act as an early warning system and therefore eliminate many decisions from ever being made. 


\section{Conclusion}

The amount of information to consider today in decision-making is nearly limitless. Most of this information is available to all the participants, which means that the information itself cannot be a competitive advantage. Rather, the interpretation and synthesis of such complex, contrasting, and disparate information is likely to become an important managerial capability that differentiates organizations from one another. Intuition, while having limitations, represents untapped potential. Therefore, we encourage executives to create space for intuitiveness in their strategic decision-making by advancing it through the individual, collective, and environmental levels. 


\section{References}

Akinci, C. and Sadler-Smith, E. (2018), "Collective Intuition: Implications for Improved Decision Making and Organizational Learning”, British Journal of Management.

Burke, L.A. and Miller, M.K. (1999), "Taking the mystery out of intuitive decision making”, Academy of Management Perspectives, Vol. 13 No. 4, pp. 91-99.

Dane, E. and Pratt, M.G. (2007), "Exploring intuition and its role in managerial decision making", Academy of Management Review, Vol. 32 No. 1, pp. 33-54.

Dane, E. and Pratt, M.G. (2009), “Conceptualizing and measuring intuition: A review of recent trends", International review of industrial and organizational psychology, Vol. 24 No. 1, pp. $1-40$.

Du, K. and Jaw, Y-M. (2018), "Pacing international acquisitions: emerging markets as the new success stories”, Journal of Business Strategy, Vol. 39 No. 4, pp. 3-10.

Easton, G. (2010), “Critical realism in case study research”, Industrial marketing management, Vol. 39 No. 1, pp. 118-128.

Gremler, D.D. (2004), “The critical incident technique in service research", Journal of service research, Vol. 7 No. 1, pp. 65-89.

Gubbi, S.R., Aulakh, P.S., Ray, S., Sarkar, M.B., and Chittoor, R. (2010), “Do international acquisitions by emerging-economy firms create shareholder value? The case of Indian firms", Journal of International Business Studies, Vol. 41 No. 3, pp. 397-418.

Joshi, M., Sanchez, C., and Mudde, P. (2018), "Improving the M\&A success rate: identity may be the key", Journal of Business Strategy.

Miller, C.C., and Ireland, R.D. (2005), "Intuition in strategic decision making: friend or foe in the fast-paced 21st century?", Academy of Management Perspectives, Vol. 19 No. 1, pp. 1930 .

Salas, E., Rosen, M.A., and Diaz-Granados, D. (2010), "Expertise-based intuition and decision making in organizations", Journal of management, Vol. 36 No. 4, pp. 941-973.

Sinclair, M. (Ed.). (2014), Handbook of research methods on intuition, Edward Elgar Publishing, Cheltenham, UK. 